\title{
PRÁTICAS CRIMINOSAS, PRÁTICAS EGOÍSTAS, PRÁTICAS PROIBIDAS: O ABORTO NO DISCURSO DO MÉDICO NINO MAGNO BAPTISTA, 1930
}

\section{Georgiane Garabely Heil Vázquez ${ }^{1}$ \\ Fernanda Loch ${ }^{2}$}

Resumo: O objetivo central desse artigo é apresentar o discurso de Nino Magno Baptista, presente na fonte analisada, sobre as mulheres e as práticas de aborto numa perspectiva histórica, destacando a década de 1920. A metodologia de análise foi colocada a partir de um estudo de caso, e de análise de discurso sobre uma tese médica. Ela foi apresentada na Faculdade de Medicina da Bahia, e publicada em 1930. A tese intitulada "Estudo medico social do aborto" coloca à prova a moral feminina, além de apresentar um suposto papel social das mulheres ao longo do tempo.

Palavras-chave: Aborto; medicina; estudos de gênero.

Abstract: The central objective of this article is to present the Nino Magno Baptista discourse, present in the analyzed source, on women and abortion practices from a historical perspective, highlighting the 1920s. The analysis methodology was based on a case study, and discourse analysis about a medical thesis. It was presented at the Faculdade de Medicina da Bahia, and published in 1930. The thesis entitled "Social Medical Study of Abortion" tests female morality, as well as presenting a supposed social role of women over time.

Keywords: Abortion; medicine; gender studies.

\section{Introdução}

O aspecto do aborto provocado, encara-se como nota de amargura infinda para a sociedade sempre que se descobre em casos concretos a pratica deste mal. Amargura, porque a provocação do aborto é um crime, um atentado contra as leis da Religião, da Patria, e da Familia, que são leis por que se regem as sociedades cultas. Crime e crime que nos parece dos maiores, pela sua barbaria, demonstrando de forma bem patente a incultura moral de um povo. (BAPTISTA, 1930, p. 73).

\footnotetext{
1 Professora Adjunta do Departamento de História da Universidade Estadual de Ponta Grossa, Paraná.

2 Graduada em Licenciatura em História pela Universidade Estadual de Ponta Grossa. E-mail: ferhh28@hotmail. 
O aborto levanta discussões difíceis por ser um tema polêmico e um tabu, apesar da grande incidência de casos no Brasil, e de sua recorrência ao longo dos tempos e da história. Segundo Diniz, Medeiros e Madeiro (2017, p.653), quase 1 em cada 5 mulheres, aos 40 anos já realizou, pelo menos, um aborto no Brasil.. É um assunto que não só tem relevância política, - podendo afetar resultados eleitorais, por exemplo, - como toca na questão legal, levando em conta a legislação vigente sobre o aborto. E não só isso, o aborto também perpassa pelos julgamentos dos valores morais, que acima de tudo, influenciam as diferentes opiniões que circundam o tema.

Partindo do pressuposto legal, em alguns países como, por exemplo, nos Estados Unidos, o aborto foi legalizado a partir da década de 1970. No Brasil, de acordo com o código penal de 1940 e vigente até hoje, - salvo os casos de aborto necessário para preservação da vida da mãe, de gravidez resultante de estupro, e também de fetos anencéfalos - é proibido.

As leis que estão em vigor em determinada sociedade podem vir a mostrar e fundamentar valores e costumes presentes na mesma. $\bigcirc$ aborto esteve presente explicitamente na legislação brasileira desde 1830, que então teve mudanças em 1890, e posteriormente em 1940. (VAZQUEZ, 2005, p. 97).

De acordo com o contexto analisado, em 1930, o código que estava em uso era o de 1890:

Art. 300 - Provocar aborto, haja ou não a expulsão do fruto da concepção:

No primeiro caso: - pena de prisão cellular por dous a seis annos.

No segundo caso: - pena de prisão cellular por seis meses a um ano.

* $1^{\circ}$ - Si em conseqüência do aborto ou dos meos empregados para provocal-o, seguir a morte da mulher:

Pena: - de prisão celular de seis a vinte e quatro annos.

* $2^{\circ}$ - Si o aborto for provocado por médico, ou parteira legalmente habilitada para o exercício da medicina:

Pena: - a mesma precedentemente estabelecida, e a de privação do exercício da profissão por tempo igual ao da condenação.

Art.301- Provocar aborto com annuencia e accordo da gestante:

Pena: de prisão cellular de um a cinco annos.

*único: - Em igual pena incorrerá a gestante que conseguir abortar voluntariamente, empregando para esse fim os meios; e com reducção da terça parte, si o crime for commetido para ocultar a deshonra própria.

Art. 302- Si o médico ou parteira, praticando o aborto legal, ou aborto necessário, para salvar a gestante da morte inevitável, accasionar-lhe a morte por impericia ou 
negligencia:

Pena: - de prisão cellular por dous meses, e privação do exercício da profissão por igual tempo ao da condemnação. (BRASIL, 1890).

O código de 1890 agora já punia a gestante envolvida com a prática de aborto (o que no código anterior, de 1830, não acontecia) (VAZQUEZ, 2005, p. 98, 103), entretanto diminuía a pena se o crime fosse cometido para ocultar a desonra própria, revelando assim, como a moral e a honra feminina eram subjugadas pela sociedade, na qual o aborto era considerado "menos ofensivo" quando cometido para preservar os valores familiares e a honra da moça gestante.

A recusa de um filho ou da maternidade, por parte das mulheres/mães, não é aceita com bons olhos atualmente, assim como não era no começo do século $\mathrm{XX}$, contexto em que foi escrita a tese médica que será analisada. Meu objetivo é fazer um estudo de caso por meio desta tese, para debater sobre as práticas de aborto através do discurso do médico Baptista (1930), numa perspectiva histórica e em uma abordagem de análise de gênero. Justifico essa escolha pela própria dinâmica das práticas abortivas, terreno pantanoso em que reina silêncio e segredo. Encontrar vestígios históricos sobre abortos não é tarefa fácil. Via de regra, alguns processos-crime ou inquéritos são possiveis de se encontrar, mas a maioria das possibilidades de pesquisa estão no campo da medicina, área que por ofício "trabalha com o aborto".

Um estudo de caso, segundo Gil (2002), seria o estudo de um ou poucos objetos de pesquisa, permitindo que o conhecimento sobre tal objeto seja profundo e detalhado. Para Ventura (2007, p. 385-386), os estudos de caso têm uma grande utilidade em pesquisas exploratórias:

Por sua flexibilidade, é recomendável nas fases iniciais de uma investigação sobre
temas complexos, para a construção de hipóteses ou reformulação do problema.
Também se aplica com pertinência nas situações em que o objeto de estudo já
é suficientemente conhecido a ponto de ser enquadrado em determinado tipo
ideal. São úteis também na exploração de novos processos ou comportamentos,
novas descobertas, porque têm a importante função de gerar hipóteses e construir
teorias. Ou ainda, pelo fato de explorar casos atípicos ou extremos para melhor
compreender os processos típicos.

Os dois autores citados acima concordam que um dos maiores problemas do método seria a generalização dos resultados. (GIL, 2002; VENTURA, 2007).

Pode ocorrer que a unidade escolhida para investigação seja bastante atípica em relação às muitas da sua espécie. Naturalmente, os resultados da pesquisa tornar- 
se-ão bastante equivocados. Por essa razão, cabe lembrar que, embora o estudo de caso se processe de forma relativamente simples, pode exigir do pesquisador muita atenção e cuidado, principalmente porque ele está profundamente envolvido na investigação. (VENTURA, 2007, p. 386).

Para um melhor aprofundamento do estudo de caso, combinarei esta metodologia com a análise de discurso.

A análise de discurso, segundo Orlandi (1994), se constitui na relação entre a Linguística e as Ciências Sociais, no qual a primeira exclui a exterioridade (o contexto), e a segunda perpassa a linguagem e vai atrás dos seus sentidos:

Como sabemos, a Lingüistica, para se constituir, exclui o sujeito e a situação (o que chamamos exterioridade), e as Ciências Sociais não tratam da linguagem em sua ordem própria, de autonomia, como sistema significante, mas a atravessam em busca de sentidos de que ela seria mera portadora, seja enquanto instrumento de comunicação ou de informação. (ORLANDI, 1994, p. 53).

Quando um sujeito fala, ele não se apresenta somente enquanto um sujeito individualizado, mas também como produto de um contexto e de suas convicções e experiências, no qual diversos fatores interferem no seu discurso.

A história, o contexto e a posição social concorrem para as produções discursivas. $\bigcirc$ enunciador do discurso, portanto, não é somente um sujeito empírico, um sujeito da experiência e da existência individualizada no mundo, mas sim um sujeito discursivo, cuja história pessoal se insere na história social, ideologicamente marcada. (GONDIM e FISCHER, 2009, p. 12).

A partir desta estrutura metodológica será analisada a tese médica de autoria do médico Nino Magno Baptista e que tem como título Estudo medico social do aborto. $O$ interessante sobre a fonte, e o que teve uma grande influência no porquê da escolha da mesma para a pesquisa, é justamente essa questão do "social", no qual o médico faz alguns julgamentos morais sobre as mulheres que praticam aborto e coloca quais os supostos papéis sociais que as mulheres deveriam seguir. ${ }^{3}$

O autor, Nino Magno Baptista, natural da Bahia, é filho legítimo ${ }^{4}$ do Snr. Francisco Magno Baptista e D. Innocencia Moraes Baptista. Apresentou sua 3 É importante pontuar que nas citações e informações tiradas da tese optou-se por deixar a grafia original, sem atualizações gramaticais.

$4 \quad$ Nos dias atuais as expressões sobre filiação legítima, ilegítima, natural, bastardia ou até mesmo adulterina estão em desuso, e é conveniente colocar essa expressão neste artigo devido ao contexto da tese, e as discussões sobre honra e sobre a instituição familiar presentes aqui, apesar do aprofundamento nesses conceitos e o debate dos mesmos ficar para outro momento. 
tese à Faculdade de Medicina da Bahia em 15 de outubro de 1930, afim de obter o grau de doutor em Sciencias Medico-Cirurgicas na Cadeira de Medicina Legal. De acordo com a sua apresentação na tese, Nino Magno Baptista foi auxiliar da Maternidade Climerio de Oliveira, interno honorário da Cadeira de Propedêutica-Cirurgica no Pavilhão Lidio de Mesquita, interno do Gabinete de Electricidade Medica e Raio X no Hospital Santa Isabel, interno do Gabinete de Roentnologia Ambulatorio da Faculdade no Canella, Relator da Sociedade Academica Alfredo Britto, Director da Revista Academica, Sc. Da Congregação M. Academica, e fazia parte do círculo Catholico de Estudos e da Sociedade de Beneficencia Academica, ou seja, já tinha uma certa experiência na área acadêmica e médica. (BAPTISTA, 1930, p. 1).

A tese Estudo Medico Social do Aborto se constitui em cinco capítulos. Antes de começa-los, o autor coloca o Regulamento do Serviço Médico Legal e a lei sobre Aborto Criminoso (Art. 300, de 1890, a mesma lei já colocada no início deste artigo), como uma espécie de epígrafe do texto. No primeiro capítulo, Historia do Aborto, o autor faz um apanhado geral sobre a história do aborto na cultura de vários povos e em diversos países ao longo de tempo, muitas vezes baseado em mitologias desses povos. No Capitulo Segundo, Estudo Medico do Aborto, ele explica sobre as diferenças do aborto espontâneo e o aborto provocado/ criminoso, os sintomas anunciadores do aborto, e suas causas. No terceiro capítulo, Diagnostico Diferencial dos Abortos, o autor explica como diagnosticar se a mulher sofreu aborto natural ou provocado e também quais procedimentos seguir para o aborto terapêutico. No Capitulo Quarto, Estudo Social do Aborto, Nino Magno Baptista fala da teoria de Malthus, a opinião e a moral da Igreja Católica sobre o aborto, e a situação do Brasil em relação a sua população ser pequena comparado ao tamanho do território. No último capítulo da tese, o quinto, que tem como título A Mulher e a sua Evolução Social, o autor fala sobre as liberdades que as mulheres conquistaram, desde a Idade Antiga, passando pela Idade Média e chegando na contemporaneidade, fazendo julgamentos morais e também designando supostos papéis sociais para as mulheres.

Tendo em vista a metodologia utilizada, a tese de Nino Magno Baptista traz um discurso que reflete as suas ideias, individualmente, porém é escrita de uma posição social, - e não de uma posição neutra, sem influências, - ou seja, reflete parte do discurso médico do período, e diz muito mais do que somente o que está evidente em suas páginas.

Por se tratar de uma análise com a abordagem dos estudos de gênero, também é pertinente uma discussão teórica sobre a temática. $\bigcirc$ conceito de gênero tem várias definições e não é difícil encontrá-lo de forma equivocada para definir simplesmente a questão do sexo biológico, por exemplo. Segundo Scott, há várias maneiras de se definir gênero: "as feministas começaram a utilizar a palavra gênero mais seriamente, num sentido mais literal, como uma maneira de 
se referir à organização social da relação entre os sexos."; "gênero é, [...], uma categoria social imposta sobre um corpo sexuado". (SCOTT, 1995, p. 72).

A categoria de gênero não inclui somente mulheres nos seus estudos, mas vários outros temas que também se enquadram dentro deste tipo de análise. $\mathrm{Na}$ história de gênero, temas como sexualidade, família, crianças, vem à tona. Além disso, quando estudamos mulheres, modelos de feminilidade, sempre o fazemos em oposição ao masculino, o que implica também no estudo dos homens.

Assim como as mulheres foram oprimidas durante toda a história, a história das mulheres também foi reprimida na historiografia, que era um espaço constituído de autores homens. Não há dúvida de que as mulheres participaram ativamente de grandes e pequenas revoltas políticas, guerras, revoluções, e tiveram a sua participação na história, mas na história dos heróis, característica da história positivista, as historiadoras e historiadores não enxergavam as mulheres que ocupavam papéis ditos masculinos. Era como se a história das mulheres fosse separada da história dos homens, e não coubesse nas esferas política e econômica das sociedades, espaços quase exclusivamente masculinos.

\footnotetext{
Nesta perspectiva da "história de governantes e de batalhas", as mulheres só eram incluídas quando ocupavam, eventualmente, o trono (em caso de ausência de filho varão) ou então quando se tornavam a "face oculta" que governava o trono, ou a república, por trás das cortinas, dos panos, do trono, ou seja lá do que for, numa clara insinuação sensual/sexual que pensa que as coisas são decididas nos leitos de amantes. Estes leitos costumam ser considerados os responsáveis pelas "grandes" decisões da história, e promovem a queda ou a ascensão de governantes. (PEDRO, 2005, p. 84).
}

E quando mulheres chegavam ao poder, ao governo ou lideravam guerras, eram caracterizadas por diversos estereótipos.

\footnotetext{
Carregadas de estereótipos, estas análises reforçaram mitos ora da suprema santidade, ora da grande malvadez das poucas mulheres que ocupam algum cargo de destaque nos governos e/ou nas guerras. Engrossam este panteão as rainhas, as princesas e as donzelas guerreiras, das quais Joana D’Arc é uma espécie de arquétipo do "bem", enquanto Lucrecia Borgia, por exemplo, é considerada um exemplo do "mal". (PEDRO, 2005, p. 84).
}

Esses estereótipos são construções de gênero que se desenvolveram historicamente. E a construção das relações de gênero e do ideal tanto feminino, quanto masculino não ocorrem somente na esfera doméstica e nas relações de parentesco: 
Seus usos e significados nascem de uma disputa política e são os meios pelos quais as relações de poder - de dominação e de subordinação - são construídas. $\bigcirc$ saber [a respeito das diferenças sexuais] não se refere apenas a ideias, mas a instituições e estruturas, práticas cotidianas e rituais específicos, já que todos constituem relações sociais. O saber é um modo de ordenar o mundo e, como tal, não antecede a organização social, mas é inseparável dela. (SCOTT, 1994, p. 12-13).

Essa construção e usos do gênero também ocorre nas relações dentro do mercado de trabalho, na educação, na política e são legitimadas pelas relações de poder. Tentar romper essas relações de poder é confrontar com a ordem estabelecida. Por isso que escrever sobre relações de gênero é um ato político, assim como o movimento feminista.

$E$ mais, não podemos esquecer que essas construções de gênero, forçam e legitimam como cada pessoa, homem ou mulher, deve ser, viver e se comportar.

Por fim, neste artigo também será discutido sobre o controle exercido sobre os corpos femininos, os pensamentos católicos e feministas sobre o aborto, bem como o contexto nacional nas primeiras décadas do século $X X$, as questões morais e os supostos papéis sociais que incluíam as mulheres no período. Tudo isso pautado no discurso médico sobre o aborto.

\section{Os Médicos como Tutores do Corpo Feminino}

No século XIX, do ponto de vista médico, começou-se a enxergar a mulher, nas suas especificidades. Na metade deste mesmo século foi instituída a "ciência da mulher" (VAZQUEZ, 2005, p. 50), que junto com os cuidados médicos prestados às mulheres, foram se desenvolvendo estudos e teses sobre o corpo feminino e suas patologias, normalmente ligadas a gestação, ou ao papel materno.

A Faculdade de Medicina da Bahia fazia parte do que podemos chamar de uma elite institucional, levando em conta que foi uma das primeiras faculdades a serem criadas no Brasil, junto com a Faculdade de Medicina do Rio de Janeiro. (BOAVENTURA, 2009, p. 109-127). Além disso, possuía forte conexão com as tradições europeias de pesquisa: "A Faculdade de Medicina da Bahia torna-se um espaço privilegiado para as discussões científicas, bem como de ideias políticas e filosóficas que chegam do velho mundo que, por sua vez, "impulsionam o progresso da ciência" e as transformações sociais no império". (SANTOS, 2009, p. 4).

A medicina da Bahia tem uma relação estreita com as doutrinas médicas de Portugal, isso por motivos óbvios: a colonização portuguesa, no qual médicos portugueses trouxeram suas práticas de cura da metrópole para a colônia. (BARRETO, 2005, p. 19). 
O saber médico em Lisboa e em Salvador foi mediado pelas escolas de cirurgia e de medicina. [...] em Lisboa, destacamos a Escola Régia de Cirurgia (1825), posteriormente transformada em Escola Médico-Cirúrgica (1836); e, em Salvador, a Escola Médico-Cirúrgica (1815), convertida em Faculdade de Medicina da Bahia (1832). (BARRETO, 2005, p. 19).

No século XVIII, a elite enviava seus filhos para estudarem na Europa, a maioria em Portugal. Além deste contato direto dos médicos formados lá, também haviam os manuais de medicina que eram trazidos com esses doutores recém-formados, e também os vários professores de origem portuguesa que vieram lecionar na Faculdade de Medicina da Bahia (desde 1808, na fundação da Escola de Cirurgia). (BARRETO, 2005, p. 41-42).

Para se conquistar o grau de doutor, os graduandos da Faculdade de Medicina da Bahia, deveriam escrever uma tese com assunto médico do seu interesse, e com o avanço da obstetrícia, muitas delas foram sobre gravidez, e também sobre o aborto. (VAZQUEZ, 2005, p. 59-60). No advento da Faculdade de Medicina da Bahia, em 1832, quando D. Pedro II promoveu a Reforma da Educação Superior por meio de uma Carta Régia, - antes dessa Reforma, a Faculdade se chamava Escola Médico-Cirúrgica desde 1815, e Escola de Cirurgia no período anterior, de 1808 (ano de sua criação) a 1814, - três cursos agora eram ofertados, o de medicina, farmácia e obstetrícia. "Uma dessas modificações da nova legislação é a transformação do Colégio Médico-Cirúrgico em Faculdade de Medicina da Bahia e, aqui, ministram-se três cursos, quais sejam, Medicina, Farmácia e Obstetrícia, concedendo aos candidatos os títulos de Grão Doutor, Farmacêutico e Obstetra". (SANTOS, 2009, p. 2).

Revelando aqui a importância dos estudos sobre a saúde e a reprodução da mulher desde os primórdios da faculdade.

Até o século XVIII, o parto era feito somente por mulheres. A partir de 1750, em Portugal, o parto começou a se converter como categoria de cirurgia, fazendo com que este evento fosse controlado pelos homens e pela ciência, até a obstetrícia se tornar efetivamente especialidade médica em fins do século XIX. (BARRETO, 2005, p. 124-126). A partir dessas mudanças ocorridas na medicina da Europa, aos poucos elas também começaram a repercutir na medicina brasileira.

Ao mesmo tempo em que os médicos poderiam vir a ajudar uma mulher com alguma enfermidade a partir desses avanços da medicina, o saber médico também veio tomar controle dos corpos femininos e vigiar práticas supostamente criminosas que as mulheres faziam no ambiente privado. Práticas e saberes que eram compartilhados entre as mulheres de confiança e as parteiras. Por isso se houvessem complicações dessas práticas feitas pelas mulheres no ambiente 
de suas casas, - aqui incluso também o aborto, - somente em último caso, um médico era procurado. (PEDRO, 2003, p. 39, 40, 119, 120).

\begin{abstract}
Nesse sentido, a presença do saber médico, fundamentado "cientificamente", dá o principal tom da diferença entre o exame feito nas mulheres que eram acusadas de esconder a gravidez, no século XVII, e os casos análogos do século XX. O controle praticado pelo "conhecimento médico" sobre as entranhas das mulheres foi adquirido através da medicalização do parto, isto é, com a entrada dos médicos na vida das mulheres, e a consequente substituição das parteiras. Estes trouxeram, para o aparato jurídico-policial, conhecimentos que permitiam maior controle sobre a sexualidade das mulheres. (PEDRO, 2003, p. 119).
\end{abstract}

Outro campo que ajudou nessa vigilância para com as mulheres foi o de medicina legal, que a partir do século XIX se instaurou e se consolidou dentro do aparelho judiciário, fazendo os exames que comprovariam se a mulher fez ou não o aborto, o que ainda era difícil de confirmar antes da segunda metade do século XX. (PEDRO, 2003, p. 118). Mas "o Código Penal de 1890 contou, já em sua elaboração, com a participação do conhecimento da medicina legal." (PEDRO, 2003, p. 127).

Com o início das primeiras décadas do século XX, com o campo da medicina da mulher já generalizado e ganhando destaque, entre as teses publicadas no período, está a pesquisa do médico Nino Magno Baptista, intitulada Estudo medico social do aborto. No quinto capítulo da sua tese, com o título de $A$ mulher e a sua evolução social, Nino coloca em eminencia o suposto papel social das mulheres, além de fazer julgamentos morais das mulheres que praticaram aborto, mulheres que negam supostamente o seu mais importante valor feminino, que é ser mãe.

A partir disso, podemos perceber esse papel "legitimador" do pensamento médico sobre o discurso dos valores morais, honra e supostos papéis da mulher na sociedade do século XX, em especial até a década de 1930. Mas também é importante lembrar que este discurso é influenciado pelo contexto da época, pelo pensamento católico, - que tinha grande participação nas decisões da sociedade, - e também pelo pensamento feminista, - que lutava pelos direitos das mulheres -, ambos contra o aborto e a sua legalização, que era impensável ao contexto.

\title{
Contexto Nacional, Pensamento Católico E Feminista sobre o Aborto
}

O contexto nacional em que a tese foi escrita foi o início do século XX, que foi marcado pelo aumento da industrialização, urbanização, aumento das práticas capitalistas e também a busca pela legitimação do pensamento científico, atrelado à ideia de "regeneração" do país, e a busca do fortalecimento da nação. 
(SCHWARTZ, 2015, p. 318-351).

Salvador, nessa conjuntura, que tinha uma importância intermediária comparada com outras cidades do país, não viveu a mesma intensidade de modernização que teve o Rio de Janeiro, por exemplo, porém, também foi palco de grandes reformas. (CONCEIÇÃO, 2010).

A concepção inicial do projeto higienizador direcionou suas vistas para os problemas relacionados à estrutura e infra-estrutura urbanas e para a qualidade das habitações, contudo, não tardou em se preocupar com os hábitos da população, assumindo uma dimensão social. Ele implicou ações em três planos: o do espaço público, o do espaço privado e o da vida. (CONCEIÇÃO, 2010, p. 3).

Então além da modernização estrutural das cidades, o poder público também tentava normatizar os hábitos e controlar o modo de vida das classes populares, com seus "péssimos costumes" que contribuíam para a insalubridade da cidade, (CONCEIÇÃO, 2010) e consequentemente atrapalhavam para o desenvolvimento da nação.

Para o fortalecimento dessa nação, era necessário que as mulheres procriassem, mas não de uma maneira "sórdida" com alguma gravidez indesejada (que poderiam levar a mulher a práticas proibidas como o abortamento), e sim dentro da honra do casamento para que brasileiros "descentes" pudessem nascer, prosperar enquanto cidadãos, participar do crescimento da nação e realizar o preenchimento do território vazio. Para Nino Magno Baptista, no capítulo quarto da sua tese, o aumento da população brasileira traria benefícios se ligada a políticas de auxilio às familias necessitadas:

Para um numero diminuto de nações, o aumento da população pode trazer complexidades na sua vida econômica e social, bastante difíceis de resolver. Não é isto porem o caso do Brasil, cuja população está muito longe de atingir o numero que seria para desejar. Compete portanto ao governo secundar o esforço das familias necessitadas, em ordem, a que os filhos que delas nascerem encontrem os meios de subsistência e os recursos de instrucção e educação, para que possam viver e tornar-se cidadãos aptos para o paiz que deles tanto carece para a sua individualidade nacional.

O Brasil, precisa de ser povoado por brasileiros (grifo do autor) e obter a densidade de população que o seu vastíssimo território requer para que seja verdadeira fonte de riqueza e atinja um sólido progresso.

Como seria fácil alcançar este objetivo, e ao mesmo tempo remediar o mal social, que nesta these condemnamos, se os governos, cônscios dos seus deveres, dessem uma migalha do que se tem esbanjado, áquelles que apresentassem um numero 
maior de filhos, do que suas posses permitem alimentar e educar.

Assim teríamos um Brasil sem abortos, um Brasil de brasileiros, um Brasil grande, um Brasil progressivo. (BAPTISTA, 1930, p. 61-62).

Nessa parte da sua tese, Nino coloca como principal motivo para a prática de aborto a falta de condições da família para sustentar os filhos e educa-los, não levando em conta outros fatores para que a mulher não queira ter filhos. Mas segundo ele, mesmo que não se tenha condições de criação, não quer dizer que a gravidez deve ser interrompida:

E assim é. Não devemos dar origem a um, só ser faltando-nos o necessário para prover a vida physica, moral e intelectual.

Dizer que não devemos produzir filhos, se as nossas posses não chegam para sustental-os educal-os, não quer dizer que se eles vierem a ser concebidos, impeçamos o seguimento normal da prenhez, buscando no aborto criminoso o remédio cruciante para minorar um mal infinitamente menor, comparado com o crime que praticaríamos com essa medida aparentemente salvadora.

Não ter fecundado seria melhor, porem criar o filho é obra de paternidade, é dever sagrado a que não é lícito ninguém furtar-se. (BAPTISTA, 1930, p. 59-60).

Num contexto essencialmente sob os olhos da religião católica, também claramente podemos perceber a influência desta instituição no discurso médico da tese analisada.

O aspecto do aborto provocado, encara-se como nota de amargura infinda para a sociedade sempre que se descobre em casos concretos a pratica deste mal.

Amargura, porque a provocação do aborto é um crime contra as leis da Religião, da Patria, e da Familia, que são as leis por que se regem as sociedades cultas. (BAPTISTA, 1930, p. 73).

E no que respeita ao aborto, todos devem saber que a Egreja catholica fulmina com a pena de excomunhão os que para ele cooperarem. (BAPTISTA, 1930, p. 61). (Grifo nosso).

A Igreja Católica sempre foi contra as práticas de aborto, mas apesar disso, aconteceram discussões e divergências ao longo do tempo, sobre o feto já possuir alma desde a sua concepção ou uma animação retardada.

[...] em 1869, o Papa Pio IX adota explicitamente a teoria da personalização imediata, condenando qualquer aborto e em qualquer estágio da gravidez, determinando pena de excomunhão a quem quer que o praticasse. Essa condenação absoluta do aborto, historicamente muito recente, mantém-se como posição oficial da Igreja 
até os dias atuais. (NUNES, 2012, p. 27).

Sobre o movimento feminista, atualmente, ele tem pautas pró escolha e são a favor da legalização do aborto, o que não acontecia na primeira metade do século $X X$. Lá elas eram pró-natalistas, a favor da maternidade, e queriam proteger as mães e a infância. (TELES, 1993, p. 44).

discurso maternalista foi encampado por líderes feministas como Bertha Lutz, que aliou sua militância política e atividade acadêmica para propor, entre outros, medidas de proteção e fiscalização do trabalho feminino e infantil, concessão de licença-maternidade e garantia de um horário para amamentação durante a jornada de trabalho, além de melhorias na educação e assistência à saúde das mulheres. Apesar de identificar a maternidade como o principal papel feminino, Lutz reconhecia sua dupla dimensão natural e social, e negava a incompatibilidade entre educação, trabalho, emancipação feminina e vida familiar. Ao contrário, defendia acesso igualitário às mulheres em todas as instâncias sociais. A concepção da maternidade como função social funcionou como ponto de partida para suas proposições, muitas das quais foram incorporadas à Constituição de 1934. (MOTT, 2001, p. 214, 216 apud FREIRE, 2011, p. 67).

Ou seja, ser contra as práticas de aborto era um consenso geral, porém isso não quer dizer que tais práticas não aconteciam, ou que não eram recorrentes, até porque era um dos poucos métodos de contracepção disponiveis na época.

\section{As Questões Morais e o Suposto Papel Social das Mulheres}

Para a sociedade do ano de 1930, toda mulher deveria seguir o seu suposto papel natural, que é o de ser mãe. Qualquer negação a esse papel era considerada uma patologia, levando os médicos a exercerem uma espécie de controle sobre o corpo feminino. (VAZQUEZ, 2005, p. 60). Esse controle sobre a mulher e, portanto, sobre o seu corpo, decidiam se a mulher era honrada, se cumpria com o seu papel de boa mãe, ou se era vista negativamente perante a sociedade. Por isso a medicina, as mulheres e a moral, honra e "bons costumes" estavam interligados. Nino Magno Baptista estabelece em sua tese qual é o papel social da mulher:

[...] e vemos então as demi-viérges, que Paris acclama e que os Yankees embalam, acariciando-as como um produto seu, irem perdendo, nestes desfreios de mocidade incontida, a honra, a compostura e a dignidade e fazendo mil esforços, mascarandose, para que não se descubram os seus segredos, enveredando quantas vezes pelo crime do aborto, privando-se do ideal mais sagrado da mulher, o ideal de acariciar, 
ao aconchego do lar, o fruto do seu ser, o ideal sublime da maternidade. (BAPTISTA, 1930, p. 72). (grifos nosso).

Aqui ele põe que o "ideal mais sagrado da mulher" é o "ideal sublime da maternidade", e que a perca da honra e da dignidade, consequentemente levando ao crime do aborto, priva a mulher desse "ideal".

Mas além de uma boa mãe, a mulher deveria ser honrada. Ao longo do tempo, foram se construindo ideais de feminilidade que as mulheres são condicionadas a seguir. Comportamentos, características físicas, espaços, afazeres e trabalhos que são associadas ao feminino, às mulheres, e que servem aos interesses de uma sociedade patriarcal, que trazem mudanças (cômodas à sociedade) e permanências nas relações de gênero. $\bigcirc$ feminino está sempre ligado ao delicado, à etiqueta e ao cuidado tanto com os outros, quanto com si mesma, a servir a família e também a obedecer ao pai, e depois ao marido, ou outra figura masculina do seu convivio:

Assim o casamento era a entrada na vida social para a mulher, quando ela iria cumprir seu objeto de ser mãe, esposa e dona de casa, que para a sociedade da época era o mais importante na vida de uma mulher. Pois segundo o discurso dessa sociedade paternalista a mulher deveria se resguardar a casa, obedecendo seus pais e se mantendo virgem antes do casamento, depois desse (pai) obedecendo seu marido, o honrando, cuidando da casa e dos filhos. Para tanto a mulher não precisava e principalmente não deveria sentir desejo. (MOISÉS, 2014).

Ou seja, não deveria sentir desejo, nem expressar a sua sexualidade. Por isso, quando mulheres solteiras engravidavam, tentavam esconder ao máximo a gravidez dos olhares vigilantes da sociedade. Olhares que muitas vezes coagiam a moça a tentativas de aborto e na falha deste, o infanticídio. $O$ código penal de 1890 referente ao aborto, como já foi dito, diminuía a pena da gestante se o aborto fosse cometido para o ocultamento da desonra própria.

capítulo quinto da tese de Nino Magno Baptista, fala sobre essas normas sociais que as mulheres deveriam seguir:

$\mathrm{Na}$ edade contemporânea teve a mulher uma phase de apogeu antes de conhecer a degradação do vicio.

[...] Mas, com a morte, ceifando na Grande Guerra milhares e milhares de homens, todos os dias foi a mulher penetrando a pouco e pouco nos afazeres masculinos e compenetrando-se tanto desta sua contucta que proclamou a liberdade absoluta, quando a relativajá lhe era por demais suficiente. E assim começaram os desmandos, e a mulher também começou a ficar sem cabelos, sem juízo, sem roupa, e quase 
que bem podíamos chegar ao extremo de dizer que sem Patria e sem Ideal.Não mais amamentou o filho, não mais o acarinhou, procurando educal-o. Votar é o seu sonho, e complemento da sua igualdade como o homem. Nos salões, baila as mais estrambóticas dansas, embriaga-se ao Champagne, despe-se nos banhos de mar, perde a educação, os modos femininos de delicadeza e de affecto. [...] Mas, não são somente as semi-virgens que são levadas à pratica de aborto criminoso. São as casadas, as viúvas, todas as que vivem na orgia das sociedades dos jazz-bands, dos black-bottons, dos maillots, dos films, dos theatros impudicos; todas as que correm atraz do outro, das perolas, dos brilhantes, das sedas e dos faustos; as que frequentam as alcovas dos entorpecentes como o opio, a morfina, cocaina, veronal, ether, e tantos outros, muito embora lhe sirvam para dissipar a consciência, prestes como estão a explodir em crimes, e em toda a sorte de desvarios. (BAPTISTA, 1930, p. 70-72. Grifo nosso).

Outor explicitamente coloca no seu texto que liberdade não é algo que as mulheres deveriam ter, porque a "liberdade relativa já the era por demais suficiente". Ele se empenha em reafirmar o lugar da mulher, numa clara divisão entre papéis femininos e masculinos. Ele nega toda a visibilidade e espaço que elas ganharam nos últimos anos, e caracteriza essas mudanças que aconteceram com a "Grande Guerra" como uma coisa negativa para toda a sociedade e até mesmo para a Pátria. E a Guerra, além de afetar o número de homens, mudou - papel social das mulheres, que foram para a esfera pública, - mencionado ali pelo direito ao voto, por exemplo, que aproximadamente dois anos depois da publicação da tese de Nino Magno Baptista, as mulheres o tiveram assegurado, em 24 de fevereiro de 1932, no governo de Vargas, - e mudaram sua postura, (usando poucas roupas nos banhos de mar, bebendo e dançando, tendo "hábitos masculinos"), que acabam por desiquilibrar o ordenamento social. Sendo o afeto algo supostamente inerente ao feminino, o que seria do corpo social quando as mulheres não mais "amamentarem os filhos, não mais os acarinharem", e se dedicarem a práticas que as afastam dos seus papéis sociais? A revolta dele, enquanto homem, falando sobre aborto, parte disso. $O$ aborto, na concepção desse médico, também é apresentado como um dos males desses novos tempos em que a mulher ganha mais liberdade, e vai perdendo sua feminilidade.

As mudanças em relação à condição feminina na virada do século tiveram a influência do desenvolvimento industrial e urbano, o maior acesso à educação escolar, juntamente com a difusão da imprensa feminina, que realçava a importância do seu caráter e de sua educação para a sociedade, como também um espaço para revelar seus anseios e / ou desejos. (MATOS, 2013, p. 3). 
Ver as mulheres tomarem conta dos seus corpos, no mínimo que fosse, era uma forma de quebra da ordem social de organização das famílias e das relações de gênero, no qual de alguma forma penetrar nos afazeres masculinos, despir-se nos banhos de mar, ou perder os modos femininos de delicadeza e afeto, seria apenas o começo da perda da honra e bons costumes, levando no fim, ao crime, "crime que nos parece dos maiores pela sua barbaria, demonstrando de forma bem patente a incultura moral de um povo," (BAPTISTA, 1930, p. 73) o aborto. "São estas as que procuram abortar, são estas as que, por justas juízas, Deus não consente que sejam mães." (BAPTISTA, 1930, p. 72).

$A$ indignação do autor parte de que, ele, enquanto homem, sente que está perdendo privilégios que até então não eram questionados. $E$ essa discussão sobre o aborto, fora do campo propriamente dito da medicina, na questão do "social" e da "evolução social das mulheres", presentes em sua tese, se aparecem muito mais ligadas a manutenção do status quo masculino, do que realmente uma preocupação ligada à vida do feto, ou à vida das mulheres que abortam.

\section{Considerações Finais}

O aborto na concepção do Nino Magno Baptista era um crime, um ato de barbárie e um mal decorrente da "liberdade" e das mudanças sociais que estavam atravessando o começo do século XX. Para o médico, era um ato egoísta, que afetava e prejudicava a Familia, o Estado e a Igreja. Esperava-se das mulheres do período, a aceitação do seu papel maternal, que era supostamente natural, sem contestações, e que a negação deste, implicaria na perca da sua honra e da dignidade, a privando do que seria o "ideal mais sagrado da mulher".

$\mathrm{Na}$ análise desta tese, percebemos que a partir das mudanças ocorridas no começo do século XX, - como a maior liberdade conquistada pelas mulheres e transformações nos supostos papéis sociais exercidos por elas, etc. - o médico coloca que o aborto seria um reflexo dessas alterações. E a maior parte da indignação deste médico se parte justamente da perca de privilégios masculinos inquestionáveis até então. Enquanto médico, homem, Nino Magno Baptista destaca na sua tese de medicina, a parte "social" do aborto, ou a "evolução social da mulher", transparecendo sua preocupação com a liberdade das mulheres no seu contexto, com a manutenção do status quo masculino e da ordem, mais do que a preocupação com a vida do feto e a vida das mulheres que fazem o aborto.

médico na sua posição de poder dentro do contexto estudado, se coloca enquanto representante da ciência, e mostra a "perversidade dos novos tempos", buscando também orientar sobre as leis morais vigentes, legitimando-as. Ao analisarmos a tese, não nos deparamos somente com o autor enquanto indivíduo, mas com o autor enquanto resultado do seu próprio contexto histórico-social, refletindo também parte do discurso médico do período, tangenciando então, o 
seu discurso, sua exterioridade, sua história e seu sentido. (ORLANDI, 1994).

O que se quis investigar neste trabalho são essas conexões que existem entre as práticas de aborto, o poder da medicina e do discurso médico, e o reflexo deste poder sobre as mulheres e o discurso de moral social existente em 1930.

\section{Referências}

BARRETO, Maria Renilda. A Medicina Luso-Brasileira: instituições, médicos e populações enfermas em Salvador e Lisboa (1808-1851). Tese de Doutorado. (Doutorado em História das Ciências da Saúde) - FIOCRUZ. Rio de Janeiro, 2005.

BAPTISTA, Nino Magno. Estudo medico social do aborto. Tese. Faculdade de Medicina da Bahia, 1930. Acervo da Biblioteca da Área de Saúde da Universidade Federal do Paraná.

BOAVENTURA, E. M. O Estado e a educação superior na Bahia, uma perspectiva histórica. Salvador: EDUFBA, 2009. pp. 109-127.

BRASIL. Decreto ${ }^{\circ} \mathbf{8 4 7}$, de 11 de outubro de 1890. Título X: dos crimes contra segurança de pessoa e vida; Capítulo IV: do aborto. Disponivel em: <http:// www2.camara.leg.br/legin/fed/decret/1824-1899/decreto-847-11-outubro1890-503086-publicacaooriginal-1-pe.html>. Acesso em: 21 dez. 2017.

CONCEIÇÃO, Carlos Lima da. A Bahia e a "civilização": a cidade do Salvador no Brasil republicano. Revista Eletrônica Multidisciplinar Pindorama. Instituto Federal de Educação, Ciência e Tecnologia da Bahia, IFBA. N. 01. A. 1. Ago. 2010.

DINIZ, Debora; MEDEIROS, Marcelo; MADEIRO, Alberto. Pesquisa Nacional de Aborto 2016. Revista Ciência e Saúde Coletiva. 22 (2), 2017, p. 653-660.

FREIRE, Maria Martha de Luna. Maternalismo e proteção materno-infantil: fenômeno mundial de caráter singular. Cadernos de História da Ciência. Instituto Butantan. Vol. VII (2) Jul/Dez 2011.

GIL, Antonio Carlos. Como Elaborar Projetos De Pesquisa. São Paulo: Atlas, 2002.

GONDIM, Sônia Maria Guedes; FISCHER, Tânia. O Discurso, a Análise de Discurso e a Metodologia do Discurso do Sujeito Coletivo na Gestão Intercultural. Cadernos Gestão Social. Vol. 2, No 1, 2009. P. 9-26

MATOS, Paulo Roberto; ABRANTES, Elizabeth Sousa. Virgindade, Uma Questão De Honra: sexualidade feminina na São Luís republicana (1880-1920). In: XXVII Simpósio Nacional de História. Conhecimento Histórico e Diálogo 
Social. ANPUH. Natal, 2013.

MOISÉS, Leila Raquel dos Santos. Honra, Sedução e defloramentos: Moralidade, relações e proibiçãoem Limoeirodo Norte (1932-1949). In: XIVEncontroEstadual de História do Ceará, 2014, Fortaleza. Disponivel em: <http://uece.br/eventos/ eehce2014/anais/trabalhos_completos/103-9416-30072014-205449.pdf>. Acesso: 21 fev. 2017.

NUNES, Maria José Rosado. O tema do aborto na Igreja Católica: divergências silenciadas. Ciencia e Cultura. Vol. 64, No. 2, São Paulo, Abr/Jun, 2012.

ORLANDI, Eni Puccinelli. Discurso, Imaginário Social e Conhecimento. Em Aberto. Ano 14, N.61. Brasilia, 1994. P. 53 - 59.

PEDRO, J. M. (org.). Práticas Proibidas: Práticas costumeiras de aborto e Infanticídio no século XX. Florianópolis: Editora Cidade Futura, 2003.

- Traduzindo o debate: o uso da categoria gênero na pesquisa histórica. História. São Paulo, Vol. 24, n. 1, 2005, p. 77-98.

SANTOS, Adailton Ferreira dos. A Faculdade de Medicina da Bahia: Percurso e Reforma do Ensino no Século XIX. In: VIII Seminário Nacional de Estudos e Pesquisas: "História, Sociedade e Educação no Brasil". HISTEDBR, Campinas: Unicamp, 2009.

SCHWARTZ, Lilia Moritz; STARLING, Heloisa Murgel. Capítulo 13: "A primeira República e o Povo nas Ruas". In: SCHWARTZ, Lilia Moritz; STARLING, Heloisa Murgel. Brasil: Uma Biografia. $1^{a}$ edição. São Paulo: Companhia das Letras, 2015. P. 318 - 351.

SCOTT, Joan Wallach. "Gênero: uma categoria útil de análise histórica". Educação \& Realidade. Porto Alegre, vol. 20, n² 2, jul./dez. 1995, pp. 71-99.

. "Prefácio." In: Gender and politics of history. Columbia University Press, N.Y., 1988. Tradução de Mariza Corrêa. In: Cadernos Pagu (3), 1994, p. 11-27.

TELES, Maria Amélia de Almeida. Breve História do Feminismo no Brasil. São Paulo: Editora Brasiliense, 1993.

VAZQUEZ, Georgiane Garabely Heil. Mais cruéis do que as próprias feras? Aborto e infanticídio nos Campos Gerais - Paraná entre o século XIX e o século XX. Dissertação de Mestrado. (Mestrado em História) - UFPR. Curitiba, 2005.

VENTURA, Magda Maria. O Estudo de Caso como Modalidade de Pesquisa. Pedagogia Médica. Revista SOCERJ. 20 (5). Set/Out de 2007. P. 383-386. 
Recebido em janeiro de 2018

Aprovado em maio de 2018 